\title{
Technological Innovation and Democracy in the Design of Earthquake-proof Dome Buildings in Yogyakarta
}

\author{
Sonny Yuliar,' Andhika Riyadi and Wulan Sari \\ School of Architecture, Planning and Policy Development, Bandung \\ Institute of Technology, Bandung, West Java, Indonesia
}

\section{Abstract}

A settlement may be viewed as a sociotechnical network consisting of buildings and social groups that together performs a certain function. A key question that has invited considerable debate in recent literature is how a collection of human and nonhuman elements converge to jointly function, thus, delineating the boundary between indoor and outdoor environments. The purpose of this paper is to address this question by employing actor-network theory (ANT) to investigate the design and construction of earthquake-proof dome buildings within the late 2000s Sleman Regency in Yogyakarta, Indonesia. The design trajectory of these domes was shaped by local and global actors, and negotiated the boundary between humans and their environment. The empirical findings in this paper identify the disentanglement of certain local groups during the design and construction process, which led to a fragile indoor-outdoor boundary, and contested the very uses of these structures. This paper discusses the issue of bringing technological innovation into a democratic composition of a collective, chiefly by introducing ANT in the design and construction of Yogyakarta's earthquake-proof dome buildings. It also seeks to improve both scholarly understandings and existing post-disaster reconstruction practices, in turn.

Keywords: actor-network theory, composition of the collective, indoor-outdoor boundary, post-disaster resettlement, technological innovation

1 Corresponding author: yuliarsonny@yahoo.co.id. 


\section{Introduction}

On May 27, 2006, a 6.4 Richter scale earthquake struck the Indonesian island of Java, causing widespread damage in the province of Yogyakarta and its nearby regions. Although its magnitude was not extremely high, the World Bank (2006) reported considerable casualties. Shortly after the disaster, a team of geologists from Tokyo University conducted research on the affected areas and concluded they were no longer feasible for settlement. The local government used this conclusion to decide on a post-disaster resettlement program, which was supported by the World Association of Non-Governmental Organizations (WANGO) in collaboration with Domes for the World (DFTW), to provide the appropriate technology for earthquake-proof communes (Marcillia \& Ohno, 2012; Saraswati, 2007). However, when the design and construction processes were complete, the new settlement gradually transformed into a tourist attraction, rather than a town endowed with resilience, or the capacity to adapt to change (Pickett et al., 2013).

Human ecology plays an important role in the study of residential resilience (see Mainka \& McNeely, 2011; Pickett et al., 2013). Disasters triggered by natural phenomena bring about dramatic changes for people, their environment, and settlements, to which post-disaster resettlement planning must pay closer attention. A further analysis of such township leads one to issues related to indoor environments, which constitute the primary focus herein. Post-disaster resettlement planning, often implemented with the introduction of new technologies, can significantly change the shape of indoor-outdoor environments.

Generally, human ecology centers on humans and nonhuman entities, and the mutual influence between them. As a scientific field, human ecology deals with facts (i.e., the question of "how things are"), but also deals with values (i.e., the question of "how things should be") in an explicit and direct way. Thus, while human ecology considers the conditions of plantations, animals, other geographical elements, and human individuals and social groups, it also addresses questions of whether particular associations of nonhuman and human entities are desirable or not. For example, a settlement that enjoys the capacity to adapt to change is generally considered desirable, but to achieve this status certain conditions must first be realized. Dealing with complex human-environment relationships, and the facts and values underpinning them, requires a transdisciplinary approach to inquiry, which typically involves transgressing disciplinary boundaries (Russell et al., 2008; Schoot Uiterkamp \& Vlek, 2007; Wickson et al., 2006). The question of facts and values considered relevant to a problem has practical as well as theoretical importance. 
The key question addressed in this paper regards how human and nonhuman entities converge to mutually function, thus, delineating the boundary between indoor and outdoor environments. This paper will address this by employing actor-network theory (ANT) in an empirical investigation within the context of post-earthquake resettlement in the Ngelepen village Yogyakarta. Through empirical data, this paper describes the various actors and their respective roles in the design, construction, and adoption of dome buildings, and how they negotiate the boundary between humans and their environment, and between indoor and outdoor environments. The data were obtained by conducting field observations and semi-structured interviews for a two-month period in December 2010 and January 2011, as well as a two-day period in July 2018 involving 15 informants from local government, nongovernment organizations, university researchers, and local residents. Through a transdisciplinary approach, the paper contributes to scholarly understandings of how certain indoor and outdoor environments come into existence as the result of post-disaster recovery or resettlement policy practices. Therefore, its findings are relevant to post-disaster resettlement planning, architectural design, and technological innovation. The coming discussions involve a literature review on human ecology, its relevance to post-disaster recovery problems, the transdisciplinary nature of this subject, and how ANT provides a valuable method to conduct such an inquiry. Both the research design and methodology of this paper are presented, followed by the empirical findings and a discussion of the practical and theoretical contributions of this research.

\section{Scholarly Context}

While there has been significant literature on the human ecology approach to post-disaster recovery, little attention has been paid to the relation between facts and values implied within investigation. Human ecology may be employed to study a wide array of practices, such as conservation, urban settlements and infrastructures, and indigenous people living in biologically diverse areas. Marten (2001) characterized the discipline as concerning "the relationships between people and their environment" (p. 1), and emphasized its focus on the analysis of "consequences of human activities as a chain of effects through the ecosystem and human social system" (p. 3). For Marten (2001), ecosystems include everything nonhuman, such as biological entities, physical entities, and human-built structures in a particular location, while social systems include everything human, such as social organization, structure, and culture.

Human ecology plays an important role in the study of human resilience to environmental change (Pickett et. al., 2013), including natural phenomena such as earthquakes, tsunamis, and volcanic eruptions, which under certain circumstances cause disastrous outcomes. Attempts to rebuild settlements that are heavily damaged 
by earthquakes, in particular, can bring desirable or undesirable consequences to people's livelihoods and other living entities (DeClerck et al., 2006; Mordechai \& Pickett, 2018; Tafti \& Tomlinson, 2015).

Mukerji (2015) proposed an approach to post-disaster recovery that employs the concept of social capital to analyze community recovery after disaster. This paper highlights the importance of connecting social capital with broader "contexts that can dictate collective action ... and new resources that the emergence linking of capital networks can bring to the communities" (Mukerji, 2015, pp. 946-948). Thus, while human ecology addresses complex relationships between humans and environments, it also raises questions of value. In regard to post-disaster resettlement or recovery, research addressing whether or not certain relationships between humans and their environment generate resilience is a value judgment, thus, rendering it good/desirable or bad/undesirable. For example, in McKinney et al. (2015) and Mikkelson (2016), questions of value are explicitly posed in relation to environmental inequality and democracy, respectively. In investigating ecosystems, or in the design and planning of built environments, the notion of ecosystem function is also often adopted (Marten, 2001; Pickett et al., 2013). Hence, in relation to the notion of function, Vermaas et al. (2011) drew a distinction between structural description and functional description, and emphasized that "functions ... cannot be contemplated in isolation of the goals of human action and if one presumes that from the moral angle those goals can be evaluated as good or bad" (p. 15). Thus, human ecology deploys scientific facts and structural descriptions in its study of biological and physical entities, but likewise deals with questions of human-social values and moral judgments, either implicitly or explicitly.

This paper advocates for a transdisciplinary research approach to produce required knowledge. Notably, it intends to address complex problems, particularly those involving the interface between human and natural systems, and employs methodologies that reflect and respond to a problem and its given context. Additionally, it involves collaborative knowledge generation between researchers and stakeholders, which provides a "reality check" for research processes and outcomes, in turn (Wickson et al., 2006). To establish connections between facts and values (or science and morality) in a single framework of study requires transdisciplinary research, since both elements traditionally belong to separate domains of inquiry. These difficulties are reviewed extensively within the context of ecology in Latour (2004), and of science, technology, and democracy in Barrotta (2018).

Based on his work in ANT, Latour (2004) proposed an approach that is relevant to addressing the above-described fact-value distinction question within the context of human ecology. Originally formulated and furthered by Latour (1987), Callon (1986), and Law (1990), ANT offers an approach to study society and nature in a symmetric manner. For ANT, society and nature, and both social and technical entities, are not "out there" already held together by a unifying force, or a pre-given 
set of rules. Instead, they emerge from heterogeneous associations between humans and nonhumans. As they enter into association, the competencies and roles of those entities are defined through trials, with their actions subsequently dependent on their relations. Meanwhile, competencies and agencies are being contested through association-hence, the term "actor-network theory" (Latour, 2005).

By resorting to the notion of human and nonhuman associations, Latour (2004) builds a framework for studying the link between humans and their environment, and the implied connection between facts and values. By observing how scientific facts are obtained and presented, Latour (2004, p. 103) extracted two different phases: perplexity and institution. Perplexity refers to the uncertainties that emerge when new propositions are put forward, or when new human-nonhuman existences are considered, to, therefore, stimulate debates, while institution occurs when attempts are made to bring these deliberations into closure. Examining how values are conceived in discourses and practices, Latour (2005, p. 105) occasioned two subsequent phases: consultation and hierarchization. Consultation occurs when every candidate for existence is evaluated by involving a spokesperson-effectively, a jury that corresponds to its own recalcitrant problem-while hierarchization occurs when attempts are made to bring heterogeneous human-nonhuman entities into an homogeneous order of relative importance. These four phases help separate, yet reconcile, the questions of fact and value, in turn. Latour (2004, p. 109) then regrouped perplexity and consultation to question processes of consideration, and used hierarchization and institution to question how order is subsequently arranged. Essentially, the four phases are together understood as constitutive of the process of composing the "collective."

Latour (2004, pp. 136-161) elaborated on a set of instruments, skills, and knowledge commonly deployed by professions such as scientists, politicians, economists, and moralists, which are relevant to this process of composing a "collective." In perplexity, an important role here is generally played by scientists who, equipped with measurement instruments, display devices and laboratories, and make phenomena more visible. Meanwhile, politicians promote a sense of urgency or danger, and act as spokespersons of entities that demand consideration. Economists help detect invisible entities and involve them for the possible attachments between humans and nonhumans as goods and consumers or producers, while moralists function by pinpointing those who require attention. In consultation, scientists investigate all candidates, politicians form concerned parties and reliable witnesses, economists discover for each type of attachment the apposite process of interest, and moralists ensure each candidate is evaluated by a jury corresponding to its own recalcitrant problem. In hierarchization, science brings heterogeneous entities in an homogeneous hierarchy, politics make it possible to arrange incommensurable beings from largest to smallest, economy provides a common language to an 
heterogeneous set of entities, and morality reminds us to find one order, not two. Finally, in institution, scientists shelter facts, while politicians have the potential to divide collectives into friends and enemies in their requirement to bring closure.

While Latour (2004) dealt with problems of political ecology in general, this paper incorporates his work into the specific quandary of indoor settings. Through empirical research, this study employs Latour's complex four-phase framework to describe how a collection of human and nonhuman entities converge to function together, thus, delineating the boundary between indoor and outdoor environments during post-disaster resettlement.

\section{Methodology}

The research design and methodology for this paper were developed using ANT. Aside from its practical and societal importance, the post-earthquake resettlement in Yogyakarta was chosen as an empirical case study due to its theoretical relevance. The case involves cultural plurality that bred controversy (Saraswati, 2007), and concerns the introduction of new technology and innovation. It is hoped that exploring such an incident generates an empirical base for further theoretical discussions on environmental change, cultural plurality, and technological innovation. This particular case study is part of a broader research project that addresses practical and theoretical issues in technological innovation, environment, and democracy within an Indonesian context.

\section{Context of the Case Study}

Approximately 18 percent of the total area of the province of Yogyakarta in the Sleman Regency consists of 17 subdistricts, 86 villages, and 1,212 hamlets. The regency ranges from $100 \mathrm{~m}$ to $1000 \mathrm{~m}(328 \mathrm{ft}$ to $3,280 \mathrm{ft})$ above sea level, and is endowed with a wet tropical climate and rainy season, with air temperature ranges between $26-28^{\circ} \mathrm{C}\left(79-82^{\circ} \mathrm{F}\right)$, and average rainfall of $16.2 \mathrm{~mm}(0.65 \mathrm{in})$. Being adjacent to Mount Merapi-one of the most active volcanoes in the world-the Sleman Regency has fertile land, with nearly half of the area used for agricultural activities supported by irrigation infrastructure. As the regency is located along the Indo-Australian-Eurasian plate subduction line, this makes it particularly vulnerable to earthquakes. In a broader context, the spatial planning of the entire Yogyakarta province follows the so-called "imaginary axis," which derives from traditional Javanese culture and describes the journey of human life from birth, adulthood, and finally death. Mount Merapi occupies an important position in Javanese culture, as it is believed to be the central kingdom of spirits. Elements of a traditional house, or "Joglo," are also associated with certain values and norms in 
Indonesia (Dakung \& Proyek Inventarisasi dan Dokumentasi Kebudayaan Daerah, 1983; Santosa, 1997); with its rectangular form, such a building serves as a reference for which to structure traditional Javanese homes (Santosa, 1997).

At 5.53 am local time, a 6.4 Richter scale earthquake with an epicenter $20 \mathrm{~km}$ $(12 \mathrm{mi})$ south of Yogyakarta struck the Indonesian island of Java for approximately 57 seconds. Although its magnitude was not extremely high, the World Bank (2006) reported the quake caused roughly 6,000 casualties, injured 50,000 people, and displaced 500,000 others, with a total loss of US $\$ 3.1$ billion, in turn. A small village called Ngelepen located on the sloping hills in the Sleman Regency was severely destroyed following the disaster. Most of its residents including those living in nearby villages earn their livelihood from agricultural activities. Some of them work on their own lands, others as farm laborers, and a few are ranchers and sheep breeders. However, the village's ground was broken apart roughly $20 \mathrm{~m}(66 \mathrm{ft})$ in width, $300 \mathrm{~m}(984 \mathrm{ft})$ in length, and $7 \mathrm{~m}(23 \mathrm{ft})$ deep. Many houses were destroyed and some were displaced from their original locations.

Responding to the disaster, local government officials undertook urgent measures. The Sleman district's Major relocated all 32 families living in Ngelepen as well as 32 others from nearby villages, whose homes were severely damaged. Now located in Sumberharjo, the new settlement is a dome village known as New Ngelepen, which houses 64 families transferred from both regions. Formed on a $2.5 \mathrm{ha}(6.5 \mathrm{ac})$ block of land owned by the local government (and previously used for sugarcane plantations), the construction of this new town was supported by the humanitarian aid program sponsored by WANGO in collaboration with the DFTW, a nonprofit organization based in Utah. Essentially, it provided the technology to help construct these earthquake-proof settlements, known also as "monolithic EcoShell domes" (South, 2013, p. 3). However, after the design and construction processes were completed, the new settlement has since transformed into a tourism hot spot, rather than a domain built for resilience.

\section{Research Design and Techniques}

While traditional qualitative methods remain relevant for research purposes, this paper incorporates concepts from ANT to guide the study design-primarily the rule that researchers must "follow the actors" (Latour, 2005, p. 227) and the concept of "translation" (pp. 131-135). As such, relevant actors (i.e., human and nonhuman) must be chosen and subsequently followed to address the key research question; that is, various actors will play their respective roles in the path of New Ngelepen dome-settlement design, construction, and adoption. Since the resettlement program involved the introduction of new technology, this paper adopts the notion of diffusion (i.e., design and construction) and the innovation introduced, in turn (Rogers, 1983). However, while others such as Rogers (1983) focused on both communication processes and channels, this paper instead centers 
on the translations and associations between human and nonhuman actors. This was achieved by first selecting an informant from the local government who was responsible for implementing the resettlement program, and who could identify various other parties involved. From this point, a number of academics, other local government officials, an intermediary agent, and local residents were identified. During the interviews and field observations, multiple factors were explored, including the structural elements of the buildings, the site plan and environment proposed in discussions or debates within both design and construction stages, and the adoption of the new settlement. Further considered were those who took part in these deliberations, the issues associated with the nonhuman objects represented by each of the respective parties, and how translation occurred (i.e., changes in design and shifts in focal issues) during those stages. The notion of structural and functional description analyzed in Vermaas et al. (2011) were particularly helpful in guiding the exploration. Interviews and field observations were next conducted over a two-month period in December 2010 and January 2011, while documents related to the resettlement program were collected during the subsequent research period. These concerned spatial and regional planning documents obtained from the local government, and design documents from both DFTW and other local researchers. The total number of informants was 11, with interviews taking up to 60 minutes.

The data from this empirical research were partially used as a basis for completing a master's thesis (Pramularsih, 2011), which focused on the negotiation processes that shaped placemaking in the New Ngelepen settlement. However, it is acknowledged that the data contain rich information that allows for further theoretical exploration. One such element, which was not addressed in Pramularsih (2011), to address first regards the fact-value distinction associated with human and environment relationships. For this, the existing data were further coded and processed using Latour's (2004) framework of "composing the collective," and categorized according to both indoor and outdoor environmental changes, as well as the four aforementioned phases: perplexity, consultation, hierarchization, and institution. Relevant data were also sourced from websites, including other research that maintains regular updates in relation to the New Ngelepen settlement. From these sources, it was concluded that critical events occurred in the settlement during the period between 2006 and 2010. Before finalizing the results presented in this paper, two days of observations and interviews were piloted in July 2018. With regard to other research on post-disaster recovery or environmental change (Mainka \& McNeely, 2011; Mordechai \& Pickett, 2018; Mukerji, 2015), this research differs in its transdisciplinary approach through its use of ANT. 


\section{Ethical Statement}

The authors took various measures to guarantee the integrity and quality of the research. Commencing the fieldwork and interviews, all potential participants received full information regarding the purpose, methods, and intended possible uses of the study, with their safety guaranteed. Depending on mutual agreement between the researchers and each individual participant, total confidentiality and anonymity were maintained, with all informants agreeing for interview stating their voluntary willingness to take part in the study. Although there was disagreement among the participants with regard to the successes of the New Ngelepen settlement, the researchers maintained their independent position throughout the activities, and hope the results will be useful to those who contributed, as well as broader related social groups to reach resolve.

\section{Findings}

The empirical findings associated with the post-disaster resettlement program are presented in three stages concerning:

1. the design and construction of the settlement

2. the adoption of the settlement by local residents

3. the conception and adoption of the settlement as a tourist attraction in the postconstruction stage.

Findings that are relevant to changes in both indoor and outdoor environments are highlighted in each stage. How the findings were analyzed according to the framework of composing a collective is described herein.

\section{Design and Construction of the Settlement}

Prior to the presence of both WANGO and DFTW following disaster, a team of geologists from Tokyo University had conducted research on the earthquakeaffected areas in the Yogyakarta province. The team found that the geological structure of the Ngelepen area was severely destroyed by the quake and, therefore, no longer technically feasible to support settlement. This finding was reported to local government officials and used as a basis for relocation.

In July 2006, two architects from DFTW, Frederick Crandall and Rebecca South, arrived at Ngelepen and introduced their "monolithic EcoShell dome" technology through a series of talks with representatives from international agencies (such as the United Nations Development Programme and the World Health Organization) and local government officials. In South's (2013, p. 4) document Ecoshell 1 the structures are characterized as "super-strong dwellings, impervious to fire, 
tornadoes, hurricanes, earthquakes, and termites." Crandall and South assigned a local, Mr. Yoss, as a DFTW liaison to select a native academic to represent the communities. He then made contact with Professor Ikaputra from Gadjah Mada University (a government-owned college located in Yogyakarta), who is an architect with academic interests in heritage studies and disaster resilience within built environments, as well as a former member of the University Post Disaster Support Team for the Tsunami Aceh Revival Program. Mr. Yoss organized a meeting that brought together DFTW and WANGO representatives, local government officials, and Mr. Ikaputra. While the idea of strong dwellings proposed by the DFTW was widely acceptable, the dome-shaped design was challenged, especially by Mr. Ikaputra, who, in an interview, voiced his concerns by making reference to the locality's cultural environment:

The guideline that we made is about earthquake resistance, not the shape of the building. Wherever I go in Indonesia, if I introduce dome building [s], it has always been rejected; culturally different ... If I have to speak in the name of culture, I reject the project, it is against my heart. But, ultimately, I accept the project for humanitarian reason $[s]$... Civil engineers prefer strong ... monolithic structure[s], but architects look at technical aspects plus living culture.

Thus, for Mr. Ikaputra, the local communities hold certain cultural values that demand consideration in terms of building design. However, fellow colleague Professor Iman Satyarno emphasized that the structural properties of the domes and their social acceptance are two separate issues:

Look at the Monolithic Dome website ... I also design a dome building. We have made calculations. It can resist earthquake[s]. Technically, it is safe ... The structure of the building was my responsibility, but for user satisfaction, it was Mr. Ikaputra’s responsibility. In building design, there are two aspects: structure and social. I focus on the structure, the construction-technical specifications.

For Mr. Satyarno, a civil engineer who served as a consultant to the local governments, building designs should primarily respond to physical environments (i.e., physically safe domains). Responding to the controversy regarding the dome shape, Mr. Adi, who heads the Building and Environment division of the local government, held a different view on this matter, stating, "the DFTW architects introduced the dome building ... To me, if the building is maintained properly, if it is kept in its original shape, it is unique. It could serve as a marker or a reminder of the earthquake phenomenon."

Despite disagreement, the project continued to follow DFTW's original proposal. As such, Crandall led the development of the proposed dome designs and specified they be $35 \mathrm{sq} \mathrm{m} \mathrm{(277} \mathrm{sq} \mathrm{ft)} \mathrm{in} \mathrm{width,} 7 \mathrm{~m}(23 \mathrm{ft})$ in diameter, and $4.6 \mathrm{~m}(15 \mathrm{ft})$ in height. The buildings would have one doorway, and be divided into four equally 
sized rooms: living room and kitchen with no partition between them, and two bedrooms. When Mr. Ikaputra examined the design, he criticized the indoor environment by again making reference to traditional culture:

In architecture, the Joglo house is widely known as our reference ... They [DFTW architects] introduced a new design reference that may not be suitable for Yogyakarta's culture. It could be suitable only in terms of resistance against [an] earthquake ... In Crandall's design, he only provides one doorway. When people come into the building, they will enter directly the living room and kitchen ... It is a mistake. In Javanese culture, the host cannot receive guests before taking a bath. In that condition imposed by the design, the host would jump out through a window, because they need to take a bath before receiving the guests ... We need another doorway.

Mr. Ikaputra then proposed an indoor design alternative that, for him, was more suitable to Javanese culture:

With my background in history, culture is the key. I did study for some time in Japan. In Japan, they succeed to combine the old and the new. It is a cultural process. Regarding dome design, I proposed a local contextualization by adding a "tritisan." At first, they rejected my idea, but at the end they accepted.

Evidently, Mr. Ikaputra prompted the Joglo be used as a reference point to model the domes, the key feature of which is the presence of a "tritisan," which, in traditional Javanese architecture, serves as a marker on a home's porch, and covers the underside space against sunlight and rain. In traditional Javanese communities, people interact not only in the outdoors and indoors, but also in between. They converse under the tritisan, while keeping their front doors open. In addition to a front doorway, a back doorway is important, as it is associated with outdoor activities at the back of a house, such as plant cultivation and sheep breeding. As the front and back are associated with very different activities that must be isolated one from another, Mr. Ikaputra's alternative indoor design, which consists of a front doorway and back doorway, ultimately divides the entire interior into one living room, two bedrooms, and a kitchen near a back door. By referring to the Joglo design, Mr. Ikaputra further divided the interior vertically by adding a mezzanine and a ladder located in the kitchen. Each room is provided with an opening, either in the form of a window or "bouvenlight" (upper window), as well as ventilation holes for natural daylight and air circulation.

In negotiating Mr. Ikaputra's design proposal, Crandall sought to adapt his vision to suit traditional culture. He proposed a design equipped with "mustoko" (a domelike roof placed on mosque buildings), which Mr. Ikaputra rejected, since it is traditionally associated with religious practices and meaning. Conversely, Crandall objected the use of a tritisan, as it would increase construction costs. After some debate, the two agreed on a compromised design that was closer to the original DFTW design in external appearance (i.e., without a tritisan, thatched roof, or any 
other decoration), but adopted Mr. Ikaputra's proposal for the interior. Crandall decided that the dome should be coated with fine plastering and white waterproof paint. Considering the tropical climate, the white color was selected to reflect the heat of the sun and, thus, maintain a low temperature inside the buildings. Although Mr. Ikaputra spoke on several occasions about local culture and mentioned the issue of cultural adaptation, an interview with a local resident, Mr. Sakiran, revealed a different interest:

If you ask each of the 71 households, none of them had previously owned or occupied a Joglo house. Their houses were already made of concrete. What triggered the polemic $[s i c]$ was the shape of dome buildings, which is very different from what they were familiar with.

As a local resident who occupied the dome building, Mr. Sakiran showed disagreement with Mr. Ikaputra's intent to reference traditional culture. In the postconstruction stage, Mr. Sakiran played a leading role in urging local residents to transform the dome settlement into a tourism attraction for economic reasons.

The site plan design stage began soon after the domes and interiors were settled. The design team included the Sleman Regent, relevant local government officials, Mr. Ikaputra, Frederick Crandall, and Rebecca South. The Regent suggested that toilet and washing facilities be located outdoors for common use, as he believed it is among traditional practice to perform washing activities outside while engaging in social interactions. The team agreed to provide one toilet and washing facility for every block of buildings, which was centrally located. The team then added public facilities such as a mosque, a kindergarten, a polyclinic, and a warehouse. The main gate of the settlement is located in the middle of the area facing toward the South Sea, in accordance with the imaginary-axis belief in Javanese culture.

An examination of the Regional and Spatial Plan Document of the Yogyakarta province (Regional Planning Agency, 2009) revealed this so-called "imaginary axis" as a straight line drawn from Mount Merapi down to Keraton (the palace of the Javanese kingdom), and ultimately to the south coast of Java. In traditional Javanese belief, Mount Merapi occupies the spirits that guide in the journey of human life, as signified by this axis. Indeed, it also served in the regional and spatial plan as a general guideline in the settlement's geographical orientation.

Several changes occurred during the actual construction phase. Upon designing the site plan, it was agreed that a communal warehouse would be built. However, it was not implemented, as local residents preferred to store their belongings inside their domes. A wall fence was added in the process, which served as a partition separating the settlement from the cemetery, located in the northern sector. 


\section{Adoption of the Settlement}

The first stage of adopting the new settlement involved selecting eligible local residents and allocating them to dome units. First priority was awarded to those who lived in the area where massive landslide occurred, and second to those whose homes were severely damaged. To prevent disruptions that could emerge from differences in spatial inequality, the local government officials resorted to a random rule (implemented by a lottery) to decide upon each resident's allocation to a dome house. Upon adopting the settlements, some could not adapt to the round shape of the buildings, thus, creating difficulties when inserting rectangular-shaped furniture. In turn, this meant residents preferred to live in their relatives' homes in other villages.

Those who stayed in the settlement made spontaneous changes to both indoor and outdoor environments. Residents were not comfortable with the communal toilet and washing facilities provided, contradicting both the Sleman Regent's and Mr. Ikaputra's suggestions; as a result, the residents built private toilets behind their dome houses. The absence of cages for livestock in the settlement also discouraged many, according to Mr. Sakiran: "We built communal cages for livestock several months after the project had been completed. The residents did not immediately occupy the buildings; they were still reluctant. They own livestock that stay up the hill. Who will look after them?"

As the majority of residents also work as farmers or ranchers, they previously stored farming equipment, harvests, and seeds inside their homes. For cooking needs, many were still dependent on firewood. An interview with an informal leader of the people explained:

the dome buildings could be suitable for small families that do not depend on farming activities. For farmers, the buildings are not suitable. Such families own many devices and tools. They need much more space for the devices, tools, and harvests. We then built communal cages. Almost all families own livestock ... The addition of [an] extended kitchen is not permissible. However, not all householders can afford to purchase gas for domestic needs. Some of them still use firewood for cooking ... In such cases there is no option other than to add an extended space to function as a kitchen.

Early into settlement adoption, conditions were hot and bright due to minimal vegetation and a glare effect emitting from the white paint of the buildings. In the domes' design stage, the color choice was decided by considering the indoor environment, while apparently disregarding the outdoor experience. The importance of vegetation in creating a comfortable outdoor area was also not addressed while designing the site plan. During the day, the mezzanine room on each building's second floor is relatively hot because of the shallowness of the space between itself and the roof, while in the rainy season, water seeped into some domes through the 
porous walls and floors, which made the walls moist. An interview with Mr. Sakiran revealed more: "When we discussed the site plan, we agreed to maintain the Yogyakarta's culture ... To me, this is not only about culture, but also how to make the dome house comfortable. Apparently, when raining the rainwater seeped into several houses."

Facing uncomfortable conditions, the residents began to make various adjustments to indoor and outdoor environments. They began to plant trees and vines, which were grown on one side of the dome for coverage, therefore, reducing heat and glare. Residents also added tritisan and canopies atop door frames, windows, and vents to prevent rainwater from entering their homes. They also added a semipermanent gazebo that directly attached to the dome house, and a larger canopy to create enough open space for residential activities.

\section{Tourists' Turn}

The emergence of Yogyakarta's dome settlement has attracted the attention of people from nearby villages and abroad. Since the early stage of its construction, many visitors had come to explore the outdoor and indoor environments of the new town. Mr. Sakiran, who led the development of tourism in New Ngelepen, described the situation:

In the beginning, it was not a deliberate process. When the dome buildings' construction began, people from nearby villages and elsewhere came to visit this area. They seemed to be interested in the shape of the buildings, their features, and construction method. Realizing that the visitors kept increasing in number, they came here by cars or motorcycles, and brought their children; I and my friends were thinking of providing services to those visitors. We provided services for parking and information regarding dome buildings.

The local government also responded to the emerging attraction of the New Ngelepen village. Mrs. Nunuk of the regional planning office described the government's response:

In the beginning, because of the earthquake, the area was designated for a resettlement. But because of its uniqueness, we develop[ed] it as a tourism attraction. We have developed several tourism packages that explore other heritage buildings such as Boko Queen Temple and Green Temple. Now we have included the dome settlement into a single tourism package. It started in 2010. Thus, we decided that dome settlement will only be developed in New Ngelepen, not in other areas, to keep its uniqueness. The main objective is for local economic empowerment. We have provided trainings $[s i c]$ to create attractions such as a Teletubbies performance.

As the settlement gradually transformed into a tourist attraction, the number of visitors continued to increase, and the demand for services soon developed. The residents subsequently formed a local organizing group led by Mr. Sakiran, who together developed tourism services such as homestays, information services, 
and other attractions. Its organizers continue to earn revenue from these facilities, which are shared between all involved parties. However, as their activities developed, a number of issues emerged:

There is a human resource issue. I don't blame the residents. They used to be traditional farmers; they don't know tourism at all. If they see a piece of land, no matter how small it is, they will immediately cultivate something on that land. But this kind of habit makes things messy ... [a] lack of aesthetic. This habit is not appropriate for tourism ... But that is the challenge ... not easy. To manage the tourism services, we need to learn how to serve visitors, how to provide information to visitors. But the residents are reluctant to learn. If we could develop the area into a tourism destination, we could earn money from it. We could make promotion via television programs. (Mr. Sakiran)

Despite the constraints described by Mr. Sakiran, the tourism activities continue and bring about gradual changes to the indoor and outdoor environments of the dome settlement. Some of the residents have since opened kiosks that sell food and beverages, while others make toys as souvenirs and objects for stage performances, such as clown costumes and Teletubbies statues. Gradually, the residents began to make the dome buildings colorful and even agreed to name the surrounding hills "Teletubbies Hill."

\section{Discussion}

This section presents the research findings in relation to the "composition of the collective" framework, and, more specifically, to the settlement's design and construction stage, as well as its adoption of the domes turned tourist attractions. This will feed into the four perplexity, consultation, hierarchization, and institution phases to demonstrate how human and nonhuman associations delineate the indoor-outdoor boundary, and help define the New Ngelepen settlement. This section next discusses how the results may be used in the practices of post-disaster resettlement policy, and their contribution to the relevant literature.

\section{Indoor-Outdoor Delineation as Composition of the "Collective"}

\section{Perplexity}

Although earthquakes are not a new phenomenon to Yogyakarta's residents, the DFTW architects brought with them new perspectives through their scientific demonstrations. They sought to draw the residents' attention to the groundlevel shock triggered by the earthquake, and how that propagates through the structural elements of their architecture. Likewise, they focused on how best to counter the effects of the quake through the construction of resistant structures 
(i.e., the monolithic dome houses). Other groups of scientists, such as the geologists from Tokyo University, made visible the geological conditions of the areas touched by disaster. As different researchers from local colleges took part in either scientific grouping, both considered opposing perspectives: the building structure and indoor environments, and the geological structure and outdoor environments. At first, the local government focused on the latter in its post-earthquake resettlement program, then on the geologists' findings. However, the DFTW's monolithic dome technology, with its emphasis on super-strong dwellings, drew the government's attention to the interior. Meanwhile, Mr. Ikaputra reminded every party to consider traditional Javanese culture therein, as embodied in the Joglo design, with its own dual indooroutdoor orientation, while Mr. Sakiran emphasized the growing number of tourists visiting the dome settlement with their cars, motorcycles, and children. Thus, in the Ngelepen post-earthquake resettlement, the indoor-outdoor environments became associated with various humans and nonhumans who were variably considered by scientists, local government figures, and by individuals such as Mr. Ikaputra and Mr. Sakiran alike.

\section{Consultation}

During the entire process of dome settlement design and construction, ground quake and geological conditions were well represented by the researchers, as various scientific results circulated from one meeting to another. One key formal requirement when implementing the resettlement project concerned the participation of local residents, for which Mr. Ikaputra was assigned as a local representative. However, while he constantly spoke on behalf of traditional Javanese culture, he failed to adequately represent the residents themselves, including their habits, augmented practices, environment, and livestock needs. While the Joglo represents certain culture preferences among the Javanese communities, it did not speak well for the local residents in Ngelepen. Since the beginning of the construction process, the dome-shaped buildings had attracted the attention of visitors, but it was only Mr. Sakiran and his colleagues who consulted tourists regarding their demand for services. Only in the late post-construction stage did local governments confer with those visitors (as tourism consumers) and the local residents (as tourism producers). Thus, in the design and construction of New Ngelepen, the indoor-outdoor boundaries were delineated without sufficient consultation with local residents and visitors.

\section{Hierarchization}

During the domes' design and construction processes, heterogeneous entities were brought together to agree on how best to rank and compose the new settlement. Trials were conducted to order several elements, including the earth and occasional ground quakes, landslides and the geological conditions beneath the ground, the dome buildings with their quake-proof structural features, the Joglo house with its historical texts, the imaginary axis of Javanese culture in the Regional and Spatial 
Plan Document, ambient air, the nearby river, plantations, livestock, Mount Merapi, and the South Sea. Evidently, DFTW's architects constructed dome buildings with indoor arrangements as sturdy residential dwellings, Mr. Ikaputra modified the interiors and added a tritisan to build associations with the Joglo house and Javanese culture, the local government officials (supported by Mr. Ikaputra) constructed communal toilets and washing facilities at the heart of the dome settlement (chiefly to promote a sense of community among residents), and, by making reference to the imaginary axis in the Regional and Spatial Plan Document, the designers then implemented the overall geographic orientation of the settlement facing toward the South Sea.

During the design and construction stage, local residents and visitors were relatively silent, as they were represented by "Javanese culture" or considered strangers; however, they began to make their presence known in the post-construction stage. Residents planted trees and vines to make indoor and outdoor environments more comfortable and healthy, built communal cages to bring their livestock back into their environment, and constructed additional buildings (e.g., storage facilities, backside kitchens, and toilets) to expand their indoor activities. Upon consulting visitors and the local government, Mr. Sakiran and his colleagues began to consider the settlement as a tourism commodity, and built parking lots, homestay facilities, and kiosks. Thus, the particular shapes that resulted were due attempts to order heterogeneous entities and priorities in the new dome settlement, including safe indoor spaces with quake-proof buildings for DFTW's architects, culturally attached indoor-outdoor environments for Mr. Ikaputra and the local government, spaces supporting agricultural livelihood for many of the local residents, and indooroutdoor settings supporting tourism consumption and production for Mr. Sakiran's party.

\section{Institution}

The DFTW architects' front doorway design drew a clear boundary between indoor and outdoor space, with emphasis on interior safety from external threats. However, the addition of a back doorway following Mr. Ikaputra suggestion made this border porous. In the post-construction stage, the local residents were adding extra buildings around the back to expand indoor activities and build connections to the outdoor environment. This could potentially reduce the safety of the expanded interior, since the additional buildings were not constructed as part of the monolithic structure. To prevent disputes triggered by residential preference, the local government officials employed a random rule for allocating tenants to buildings. However, as the settlement transformed into a tourism attraction, the dome buildings became a commodity (as homestay facilities or objects of attraction), with some gaining more visitor preference than others. Thus, attempts to institutionalize the heterogeneous entities into a durable collective with a clearly delineated indooroutdoor environment faced counterinstitutional pressure. As people from nearby 
areas and abroad visited the settlement, new associations have developed between the residents, the entities in the settlement, and the visitors themselves. Decorations were added to make the domes appear visually similar to the "Teletubbies" homes, and this, in turn, transformed the settlement into an attraction for visiting kids. The association between the domes' geometric shape, its monolithic structure, and the ground quakes has gradually disappeared, but new associations with visitors' worlds have emerged. As such, it is important to now present the human and nonhuman elements that helped delineate this indoor-outdoor boundary, and organize the New Ngelepen dome settlement into a single picture following Latour's (2004, p. 115) framework (Figure 1).

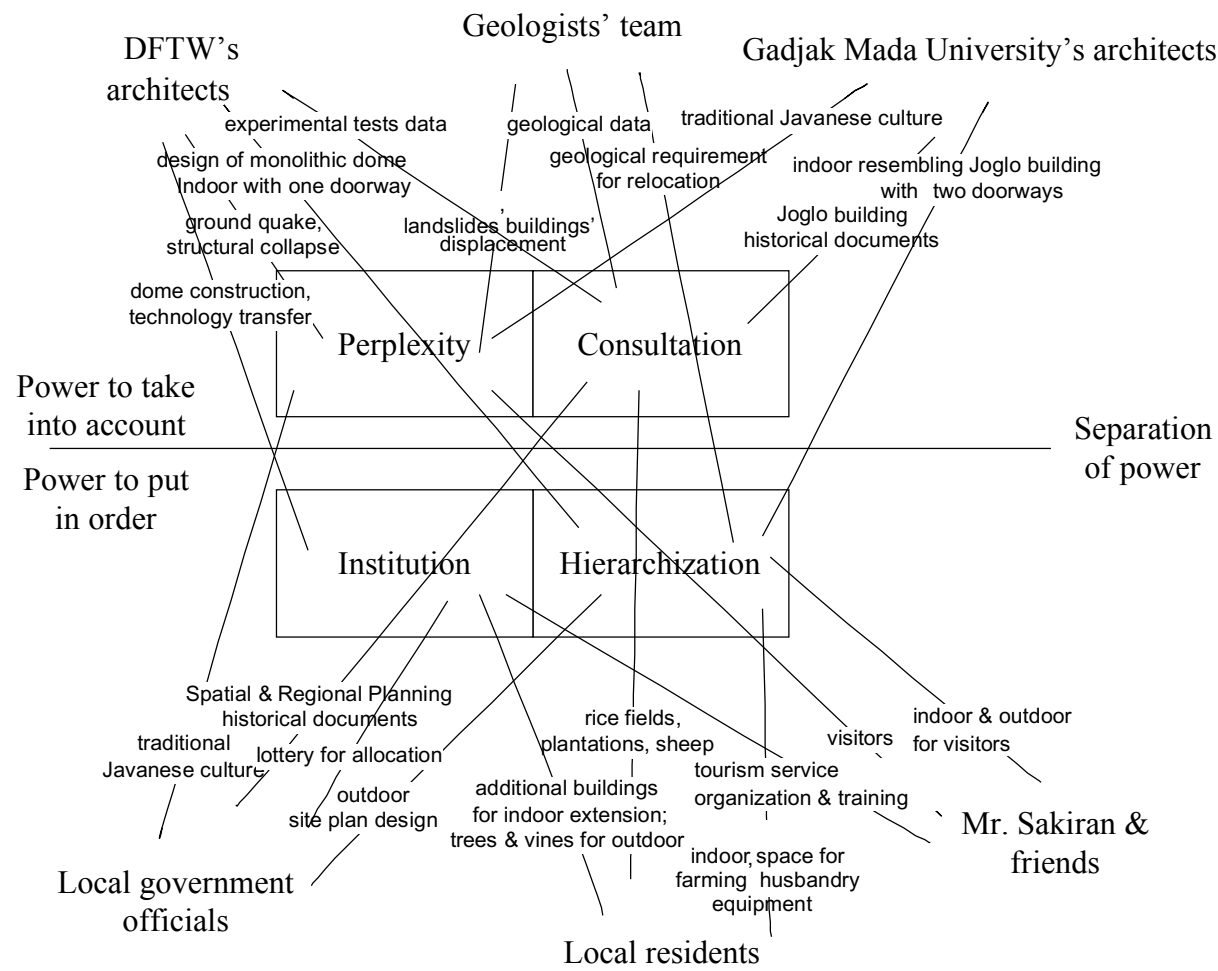

Figure 1. Various parties involved in the composition of the New Ngelepen dome settlement as a heterogeneous collective, demonstrating a lack of representation for local residents and visitors, contested indoor-outdoor designs, and both institution and counterinstitution.

Source: Figure adapted from Latour (2004). 


\section{Relevance to Post-disaster Resettlement Practice}

The results highlight lessons that are relevant to post-disaster recovery and resettlement policy practices employed to improve outcomes. They suggest that in post-disaster resettlement policy, it is important to analyze and address the consequent changes in both indoor and outdoor environments in separate but interrelated ways. As the Ngelepen case demonstrates, attempts to protect interior spaces by adopting a certain construction technology did not fully consider the consequences for the settlement's outdoor counterpart, while the design of the site plan imposed limitations for indoor activities. Since both spaces are interrelated, the design and construction of said technologies must consider their connectivity.

In post-disaster circumstances, the level of uncertainty is high in terms of what and how outcomes have been exerted, as well as who has been affected. Instead of focusing on technical functions and cultural meanings in a separate and independent manner, it is of analytical benefit to direct attention toward associations of human and nonhuman entities. For this reason, the interaction between various types of science becomes important. In the Ngelepen resettlement case, had agriculture and tourism researchers been involved in the earlier stage of the new settlement construction, the local residents and visitors would have been better represented. While cultural context is crucial (Marcillia \& Ohno, 2012), one should not jump to either cultural typology or category for justification. Instead, it is better to explore different voices that represent various social groups affected by such environmental change, both in terms of indoor and outdoor settings. Circulation of various scientific facts related to such environmental transformation could help numerous social groups in consultations, and in developing a bigger picture of the "collective." As the level of uncertainty regarding the effects of disaster is high, no one is certain about how to best order life within phases of recovery. Instead, different social groups likely bring their own preferred criterion for ordering. In these circumstances, it is important to explore each individual version, and combine them in an homogeneous hierarchy by making distinctions between indoor ordering and outdoor ordering.

The findings discussed in this paper draw on the theoretical work of Latour (2004) to investigate a practical case of a post-disaster resettlement problem that involves the diffusion of new technology. It is believed the results may be instructive and improve understanding for other cases and broader geographical contexts of postdisaster recovery or disaster risk-reduction policies. Ideally, they will improve wider outcomes, particularly as such cases are characterized by unanticipated social and environmental changes, by which attempts to mitigate these would likely involve technologies (e.g., buildings and infrastructures) new to the many affected social groups. 


\section{Contribution to Relevant Literature}

The results draw on the notion that an heterogeneous association exists between humans and nonhumans, as proposed by ANT_-within the context of human ecology, the theory's transdisciplinary approach to inquiry into fact-value distinction problems particularly clarifies. The results show that both indoor and outdoor environments do not merely exist "out there," but instead come alive through the provisional associations between humans and nonhumans, which, in actual situations, evolve through trial. Moreover, these two spaces are distinct and not completely detached from one from another.

Results in this paper also have implications for the literature on the diffusion of innovation, particularly in addressing what Rogers (1983) referred to as "the judgments as to the desirable and undesirable consequences of an innovation on individuals and their social system" (p. 381). Hence, presenting such findings within a "composition of the collective" allows for these very consequential judgments of innovation, as well as for broader social groups and environments to emerge, potentially enabling more inclusive and sustainable innovation opportunities, in turn.

\section{Conclusion}

The research question addressed in this paper concerns how a collection of human and nonhuman entities converge to function together, hence, delineating the boundary between indoor-outdoor environments. To address this query, it is crucial to deal with the relationship between humans and their settings, and the fact-value distinction, which, consequently, requires a transdisciplinary approach to inquire. As such, the researchers adopted an ANT framework as an approach to guide the analyses and address the research question. The post-earthquake resettlement in Yogyakarta was chosen for empirical study due to its cultural plurality and the introduction of new technology and innovation to the region.

The findings conclude that indoor and outdoor environments are not distinct and abstract entities. Instead, they come into existence through the provisional associations between humans and nonhumans, which evolve through processes of translation. These theoretical conclusions suggest that, in post-disaster resettlement policy practices, it is important to address the effects of ruin on changes in both indoor and outdoor environments in an interrelated manner. Likewise, when new technology is introduced for the purpose of disaster-risk reduction, its design and construction must, too, account for this spatial interrelationship. During postdisaster events in which the level of uncertainty is high, it is also demonstrated that value resides in exploring different voices that represent various social groups 
affected by indoor and outdoor environmental change. Since no one entity holds the knowledge to best order life in times of recovery, it would be beneficial to explore different versions of ordering within an homogeneous hierarchy, which maintains differentiation between both spaces.

The case chosen for research is limited in its variables considered, which implies limitation to the theoretical results of the paper. Cases that are beyond the scope under current review could be nature-triggered disasters that have effects widely spread across geography (e.g., mud volcanoes), as well as environmental issues that involve various stakeholders collectively deciding upon standard practices-indeed, this has been the case for some green building and settlement policies. Future research could extend the research to further test the theoretical strength and practicality of the study results on such cases.

\section{Acknowledgments}

The authors thank the local government officials of the Sleman Regency in the Province of Yogyakarta, the local communities of the New Ngelepen dome village, and Mr. Ikaputra for their collective support of our fieldwork in December 2010 January 2011 and July 2018. We thank Mrs. Anjar Pramularsih for her participation in the earlier stage of research, and Dr. Angga Dwiartama for his critical comments on the study results.

\section{References}

Barrotta, P. (2018). Scientists, democracy and society: A community of inquirers. Springer. doi. org/10.1007/978-3-319-74938-9

Callon, M. (1986). Some elements of a sociology of translation: Domestication of the scallops and the fishermen. In J. Law (Ed.), Power, action and belief: A new sociology of knowledge? (pp. 196-223). London, UK: Routledge.

Dakung, S., \& Proyek Inventarisasi dan Dokumentasi Kebudayaan Daerah (Indonesia). (1983). Arsitektur tradisional daerah istimewa Yogyakarta. Jakarta, Indonesia: Ministry of Education and Culture, Project Inventory and Regional Cultural Documentation.

DeClerck, F., Ingram, J. C., \& Rumbaitis del Rio, C. M. (2006). The role of ecological theory and practice in poverty alleviation and environmental conservation. Frontiers in Ecology and the Environment, 4(10), 533-540. doi.org/10.1890/1540-9295(2006) 4[533:TROETA]2.0.CO;2

Latour, B. (1987). Science in action: How to follow scientists and engineers through society. Cambridge, MA: Harvard University Press. 
Latour, B. (2004). Politics of nature: How to bring science into democracy. Cambridge, MA, London, UK: Harvard University Press.

Latour, B. (2005). Reassembling the social: An introduction to actor-network-theory. New York, NY: Oxford University Press.

Law, J. (1990). Introduction: Monsters, machines and sociotechnical relations. Sociological Review Monograph, 38, 1-23. doi.org/10.1111/j.1467-954X.1990.tb03346.x

Mainka, S. A., \& McNeely, J. (2011). Ecosystem considerations for postdisaster recovery: Lessons from China, Pakistan, and elsewhere for recovery planning in Haiti. Ecology and Society, 16(1), 13. Retrieved from www.ecologyandsociety.org/vol16/iss1/art13/

Marcillia, S. R., \& Ohno, R. (2012). Learning from resident's adjustments in self-built and donated post disaster housing after Java Earthquake 2006. Procedia Social and Behavioral Sciences, 36, 61-69. doi.org/10.1016/j.sbspro.2012.03.007

Marten, G. G. (2001). Human ecology: Basic concepts for sustainable development. London, UK: Earthscan.

McKinney, L., Kick, E., \& Cannon, C. (2015). A human ecology approach to environmental inequality: A county-level analysis of natural disasters and the distribution of landfills in the southeastern United States. Human Ecology Review, 21(1), 109-132. doi. org/10.22459/HER.21.01.2015.05

Mikkelson, G. M. (2016). Environmental values, human nature, and economic democracy. Human Ecology, 45(1), 131-134. doi.org/10.1007/s10745-016-9877-y

Mordechai, L., \& Pickett, J. (2018). Earthquakes as the quintessential SCE: Methodology and societal resilience. Human Ecology, 46, 335-348. doi.org/10.1007/s10745-0189985-y

Mukerji, C. (2015). Culture, nature and. In G. Ritzer (Ed.), The Blackwell encyclopedia of sociology (pp. 946-948). Malden, MA: Blackwell. doi.org/10.1002/9781405165518. wbeosc188.pub2

Pickett, S., Cadenasso, M. L., \& McGrath, B. (Eds.). (2013). Resilience in ecology and urban design: Linking theory and practice for sustainable cities. Dordrecht, Netherlands: Springer Science+Business Media.

Pramularsih, A. (2011). Place-making study in the conceptions of dome technology in settlement "Dome New Ngelepen" (Master's thesis). Bandung Institute of Technology, Bandung, Indonesia.

Regional Planning Agency. (2009). Rencana Tata Ruang dan Wilayah Daerah Istimewa Yogyakarta 2009-2029. Bappeda DIY.

Rogers, E. M. (1983). Diffusion of innovations (3rd ed.). New York, NY: Free Press.

Russell, A., Wickson, F., \& Carew, A. L. (2008). Transdisciplinary: Context, contradictions and capacity. Futures, 40(5), 460-472. doi.org/10.1016/j.futures.2007.10.005 
Santosa, R. (1997). Omah: The construction of meanings in Javanese domestic settings (Master's thesis). McGill University, Montreal, Canada.

Saraswati, T. (2007). Kontroversi rumah dome Ngelepen, Prambanan, Daerah Istimewa Yogyakarta. Dimensi Teknik Arsitektur, 35(2), 136-142. Retrieved from puslit2.petra. ac.id/ejournal/index.php/ars/article/viewFile/16744/16723

Schoot Uiterkamp, A., \& Vlek, C. A. J. (2007). Practice and outcomes of multidisciplinary research for environmental sustainability. JournalofSocial Issues, 63(1), 175-197. Retrieved from www.rug.nl/research/portal/files/10244576/2007JSocIssSchootUiterkamp.pdf

South, D. (2013). Ecoshell I (3rd ed., F. Parker, \& M. South, Eds., M. Ramirez, Illus.). Italy, TX: Monolithic. Retrieved from static.monolithic.com/pdfs/ecoshell_OLD2.pdf

Tafti, M. T., \& Tomlinson, R. (2015). Best practice post-disaster housing and livelihood recovery interventions: Winners and losers. International Development Planning Review, 37(2), 165-185. doi.org/10.3828/idpr.2015.14

Vermaas, P., Kroes, P., van de Poel, I., Franssen, M., \& Houkes, W. (2011). A philosophy of technology: From technical artefacts to sociotechnical systems. Synthesis Lectures on Engineers, Technology and Society, 6(1), 1-134. doi.org/10.2200/S00321ED1V01Y2010 12ETS014

Wickson, F., Carew, A. L., \& Russell, A. (2006). Transdisciplinary research: Characteristics, quandaries and quality. Futures, 38(9), 1046-1059. doi.org/10.1016/ j.futures.2006.02.011

World Bank. (2006). Preliminary damage and loss assessment: Yogyakarta and central Java natural disaster (English). Washington, DC: World Bank. Retrieved from www.eeri.org/ Ife/pdf/Indonesia_Yogyakarta_Preliminary_Damage_Assessment.pdf 
This text is taken from Human Ecology Review, Volume 24, Number 2, 2018, published by ANU Press, The Australian National University, Canberra, Australia. doi.org/10.22459/HER.24.02.2018.06 